\title{
FRACTIONATION OF BIOLOGICALLY ACTIVE COMPONENTS OF GRAPE SEED (VITIS VINIFERA) BY SUPERCRITICAL FLUID EXTRACTION
}

\author{
A. Calvo ${ }^{a}$ J. Morante ${ }^{b}$, Sz. Plánder ${ }^{\mathrm{a}}$ and E. Székely ${ }^{\mathrm{a} *}$ \\ ${ }^{a}$ Department of Chemical and Environmental Process Engineering, Budapest University of Technology and \\ Economics, H-1111 Budapest, Műegyetem rkp. 3. Hungary \\ ${ }^{\mathrm{b}}$ Department of Chemical Engineering and Environmental Technology, Valladolid University, Plaza de Sta. Cruz 8, \\ 47002 Valladolid. Spain.
}

(Received: 22 April 2016; accepted: 27 June 2016)

Supercritical fluid extraction (SFE) was used for fractionation of grape seed to be applied in natural products of the food, cosmetic, or pharmaceutical industry. A two-step process was developed, consisting of conventional alcoholic extraction followed by SFE with carbon dioxide. The effects of pressure and concentration of co-solvent (ethanol) at constant temperature and solvent to feed-ratio were evaluated. The antioxidant activity of extracts and raffinates was measured with the DPPH* free radical scavenging assay. It was observed that supercritical carbon dioxide can be used in the described process for fractionation of an alcoholic grape seed extract to obtain a product with noticeably high antioxidant activity and a second one with no antioxidant activity or pro-oxidant activity.

Keywords: supercritical fluid extraction, grape seed, Vitis vinifera, proanthocyanidins, antioxidants, DPPH

Nowadays, scientists aim to obtain value-added products from waste materials. The investigation of new natural antioxidants, especially those of plant origin, has become essential due to the restrictions for synthetic antioxidants in food industry, such as butylated hydroxyanisole (BHA) and butylated hydroxytoluene (BHT), suspected to be carcinogenic (Molero Gómez et al., 1996). On the other hand, pro-oxidant agents are promising in supplementary treatment of cancer patients (VALKO et al., 2007).

Grapes (Vitis vinifera) are one of largest fruit crops in the world (JAYAPRAKASHA et al., 2003), and grape extracts are reported to have several positive effects on human health, including antioxidant, anti-inflammatory, antimicrobial, anticarcinogenic, or cardiovascular activity, among others (NAKAMURA et al., 2003). Therefore, there is a growing interest in exploiting the potential of this plant product in the food, pharmaceutical, and cosmetic industry (JAYAPRAKASHA et al., 2003).

Grape seeds are a by-product from the wine and juice industry, which is disposed of by the majority of wineries. Nevertheless, they are rich in phenolic compounds, which present positive benefits on the human health, such as antimutagenic and antiviral activity or inhibition of the oxidation of low-density lipoproteins (LDL) in vitro (FrANKEL et al., 1995). Polyphenols, and mainly proanthocyanidins, present the most important group of bioactive

* To whom correspondence should be addressed.

Phone: +36 1 4632202; e-mail: sz-edit@mail.bme.hu

This is an open-access article distributed under the terms of the Creative Commons Attribution License, which permits unrestricted use, distribution, and reproduction in any medium for non-commercial purposes, provided the original author and source are credited. 
components in grape seed, which have a strong antioxidant activity in aqueous systems. Proanthocyanidins are oligomers and polymers of polyhydroxyflavan-3-ol units (catechin, epicatechin, and their isomers). These compounds show strong antioxidant activity in aqueous systems (NAKAMURA et al., 2003). Other highly active compounds apart from polyphenols are found in grape seed, including vitamin $\mathrm{E}$ ( $\alpha$-tocopherol), unsaturated fatty acids (mainly linoleic acid), or steroids. Grape seed oil is already commercialized as a food and cosmetic product, due to its content of unsaturated fatty acids and antioxidants.

In the case of Vitis vinifera grapes, extracts have been proved to be exploitable in the food industry (preservation of food products), as well as for nutraceuticals or health supplements, due to their wide range of pharmacological action, especially their antioxidant activity.

In the extraction of nutraceuticals from plant materials, the first parameters influencing the quality of the product are the plant part used as starting material, as well as the harvest season and region. Other variables affecting the process include the solvents, the extraction technology, and parameters: size, modifier concentration, extraction temperature, pressure and time and flow rate (Sovoví, 1994) used with the type of equipment employed, and the crude-drug:extract ratio. In the selection of solvents and entrainers, the Directive 2009/32/EC (European Commission, Directive 2009/32/EC, Annex I) must be taken into account. It regulates the use of extraction solvents in food or food products.

Traditionally, the extraction of the grape seed oil is performed with $n$-hexane(REVERCHON $\&$ MARCO, 2006), but cold pressing is also applied. Pressurized liquid extraction (PLE) on the grape seed oil can be applied as well, allowing to consume less time and use gentle conditions (WiJngaARD et al., 2012). The application of pressurised solvents offers some advantages over traditional methods, such as maceration or Soxhlet extraction (DE CASTRO, 2010), including enhanced selectivity and rate of extraction, due to the physicochemical properties of the solvent, which can be controlled by tuning the temperature and pressure (Dos SANTOS Freitas et al., 2013).

Supercritical fluid extraction (SFE) is an environmentally friendly alternative, mainly because organic solvent clean products can be obtained, and their natural properties are preserved due to the moderate temperatures used (MolERo GómEz et al., 1996). The most widely used supercritical solvent for separation of natural products is carbon dioxide, typically in the ranges of $10-50 \mathrm{MPa}$ pressures and $35-80^{\circ} \mathrm{C}$ temperatures. The most popular examples where this process was scaled-up to industry are the decaffeination of green coffee beans (Zosel, 1981) or the production of hop extracts for breweries (LAWs et al., 1980). Other examples include the extraction of spices, aromatic and medicinal plants, or nutraceuticals. Nowadays SFE facilities can be found on all continents. The extraction yield of grape seeds (Vitis vinifera) with supercritical $\mathrm{CO}_{2}$ leads to lower extraction yields than $n$-hexane, but the quality of the SFE extract is higher. The reason is that $\mathrm{CO}_{2}$ is selective to triglycerides, while $n$-hexane extracts fatty acids, phospholipids, pigments, and other unsaponifiable substances together with the triglycerides (Molero Gómez et al., 1996; CAO \& ITO, 2003).

The final goal of this study was to extract and fractionate antioxidant and pro-oxidant constituents from the grape seed using a two-step extraction process involving Soxhlet extraction and SFE with $\mathrm{CO}_{2}$, ideally obtaining relevant rates of yield and selectivity. In the literature the most relevant example of composed extraction process involving $\mathrm{scCO}_{2}$ is the patent developed by CATCHPOLE and co-workers (2007) for Industrial Research Limited, consisting of a composed near-critical fluid extraction process. In this patent a solution obtained previously by extracting plant or animal material with an aqueous or organic solvent is contacted with a near-critical fluid to produce a raffinate phase and a near-critical fluid, both containing compounds of different polarity. 


\section{Materials and methods}

\subsection{Materials}

Seeds from red Vitis vinifera were kindly provided by different wineries in 2012. The moisture-free content of the plant material was determined by the standard gravimetric method (European Pharmacopeia Commission, 2007). A specific amount of the plant material was placed in a Petri dish and dried in the oven at $104{ }^{\circ} \mathrm{C}$ for at least 48 hours. The moisture content is obtained from the mass reduction after drying. The extraction yield of the experiments is always expressed on a dry basis of plant material. The raw material (pure seeds from the wine industry) was milled in a mechanical cutting mill (model Fritsch Cutting Mill Pulverisette 15) up to $1 \mathrm{~mm}$ diameter in order to increase the interfacial area and to enhance the extraction. In order to avoid excessive warming of the equipment due to oil production from the seeds, the milling was performed in two steps: $2 \mathrm{~mm}$ and $1 \mathrm{~mm}$ sieve size. The grapes did not undergo any further pre-treatment before the extractions.

The $\mathrm{CO}_{2}$ for SFE of $99.5 \mathrm{w} / \mathrm{w} \%$ purity was supplied by Linde Ltd. (Budapest, Hungary). All organic solvents were purchased from Molar Chemicals Ltd. (Budapest, Hungary).

A large screening of different varieties of Vitis vinifera was performed in order to check the antioxidant activity of the seed extracts and to select a feasible starting plant material for the study.

\subsection{Extraction methodologies}

1.2.1. Pilot Soxhlet extraction. Soxhlet extraction was carried out in a pilot plant apparatus for extracting the soluble compounds of the milled grape seed, using a solution of ethanol and water in a ratio 50:50 (EtOH- $\left.\mathrm{H}_{2} \mathrm{O} 50: 50 \mathrm{v} / \mathrm{v}\right)$. The equipment consists basically of a thermostated extraction vessel, a reboiler, and a condenser. The drug was weighed (around $700 \mathrm{~g})$ and placed into the $5 \mathrm{dm}^{3}$ extraction vessel, then steeped in with the solvent $\left(\mathrm{H}_{2} \mathrm{O}-\right.$ EtOH 50:50). The solvent, extraction vessel, and reboiler were heated up with a steam jacket. The extract is collected in the reboiler, where the solvent is evaporated, flows through the condenser, and is recycled starting a new cycle. During the extraction the solvent flow rate, temperatures of the solvent vessel and the extractor were measured and registered every 30 min. Extract samples were taken ( 15 to $25 \mathrm{~g}$ ) every 5, 15, or 30 min depending on the extent of the process. The evolution of the solid matter concentration was measured by evaporating the samples collected during the extraction and comparing the mass of the liquid and solid extract. The process continued until the solid content of the extract is less than $0.1 \%$.

1.2.2. Fractionation with supercritical fluid extraction. Fractionation of the alcoholic extract was performed in a pilot-scale supercritical fluid extraction equipment of $5 \mathrm{dm}^{3}$ volume. Before the extraction, the material was mixed with a carrier (cellulose), in order to turn its viscous texture into a powdered one capable of forming a porous bed. The matrix (hydro-alcoholic extract supported by cellulose) is placed in the extraction vessel. The $\mathrm{CO}_{2}$ is cooled down to avoid cavitation in the high pressure pump and heated up again until the desired extraction temperature. If co-solvent is used, in this case ethanol, it is pumped from a separated deposit and mixed in a static mixer before entering the extractor. After flowing through the extraction vessel, the pressure is reduced by means of pressure-reducing valves. Temperature, pressure in the extractor and the separator, solvent flow, and density of the 
$\left(\mathrm{scCO}_{2}\right)$ are measured and registered, and samples are collected every $30 \mathrm{~min}$. The process is ended when the extraction yield varies less than $0.1 \%$ between two consecutive samples.

Effect of co-solvent concentration $(0-15 \% \mathrm{EtOH})$ was studied in detail at constant pressure of $30 \mathrm{MPa}$. In the case of pure carbon dioxide, the pressure was varied stepwise between 10 and $45 \mathrm{MPa}$. The temperature $\left(45^{\circ} \mathrm{C}\right)$ and the solvent flow $\left(5 \mathrm{~kg} \mathrm{CO}_{2} \mathrm{~h}^{-1}\right)$ were kept constant.

1.2.3. Fractionation with conventional atmospheric techniques: Soxhlet extraction and packed column extraction. Fractionation of the hydro-alcoholic extract (supported on cellulose) with SFE was compared with fractionation by conventional methods at atmospheric pressure (Soxhlet extraction and packed column extraction at laboratory scale) with organic solvents of different polarity (absolute ethanol, acetone, hexane, ethyl acetate). Soxhlet extraction at analytical scale took place in a conventional laboratory equipment described by De Castro (2010), using a relationship solvent to feed ratio of $20 / 3 \mathrm{ml} \mathrm{g}^{-1}$.

Packed column extraction (THIJssen, 1975) took place in a glass column (length $33 \mathrm{~cm}$; inner diameter $1.7 \mathrm{~cm}$ ), where the plant material was placed (hydro-alcoholic extract), resembling a simple batch-continuous extraction in a packed bed. Solvent was dropped continuously from the top of the column to the solid matrix with a burette. In this method room temperature was used, and the solvent flow was kept constant. Samples (20 ml each) of extract were collected in series in order to check the evolution of the extraction yield with the solvent consumption. Extraction was considered finished when the apparent colour of the last sample was clear enough, therefore, the concentration was 0 . Yields were calculated after evaporation of the solvent from the united samples.

\subsection{Evaluation of extracts}

Evaluation of the antioxidant activity of Vitis vinifera extracts and residues obtained by different methods was performed by means of DPPH method or free radical scavenging assay (Mishra et al., 2012) using a solution of the free radical in methanol. The reduction of the absorbance in solutions with different concentration of target sample was monitored at 517 nm. A spectrophotometer Camspec M501: Single Beam Scanning UV-Vis was used in the analysis. The so-called inhibition coefficient $\left(\mathrm{IC}_{50}\right)$ was used to evaluate and contrast the results: the minimum concentration of the sample needed to reduce the absorbance by $50 \%$.

\section{Results and discussion}

\subsection{Selection of the raw material}

The antioxidant activity of EtOH Soxhlet extracts (in terms of $\mathrm{IC}_{50}$ ) is shown in Table 1 . A large variation can be found in the antioxidant activity within the variety depending on region (e.g. Cabernet) as well as within the region depending on the variety (e.g. Villány). The $V$. vinifera grape selected is shown in italics. This selected extract was obtained with the mentioned solution of EtOH- $\mathrm{H}_{2} \mathrm{O}$. The antioxidant activity of the initial seed extract is noticeably higher than the other varieties tested, since the $\mathrm{IC}_{50}$ parameter is lower; therefore it is a promising raw material for the study. The moisture content of this grape seed is $9.51 \pm 0.12 \%(\mathrm{w} / \mathrm{w})$. 
Table 1. Antioxidant activity of Soxhlet extracts $\left(\mathrm{EtOH}, \mathrm{EtOH}-\mathrm{H}_{2} \mathrm{O}\right)$ from $V$. vinifera.

\begin{tabular}{lllc}
\hline Variety & Type & Harvest region & $\mathrm{IC}_{50} \mu \mathrm{gl}^{-1}$ \\
\hline Blauburger & Red & Villány & 7.88 \\
Cabernet & Red & Villány & $>25.00$ \\
Ezerfürtü & White & Kunsági & 8.97 \\
Kékfrankos & Red & Kunsági & $>25.00$ \\
Rizlingszilváni & White & Kunsági & 7.53 \\
Cserszegi füszeres & White & Kunsági & 8.74 \\
Bianca & White & Kunsági & $>25.00$ \\
Tramini & Red & Kunsági & $>25.00$ \\
Othelló & Red & Villány (Gere) & 7.33 \\
Oportó & Red & Villány (Gere) & 7.90 \\
Kékfrankos & Red & Villány (Gere) & 9.05 \\
Syrah & Red & Villány (Gere) & 10.45 \\
Tempranillo & Red & Villány (Gere) & 8.32 \\
Cabernet & Red & Villány (Gere) & 7.98 \\
Cabernet & Red & Gödöllö & 10.58 \\
Othelló & Red & Gödöllö & $>25$ \\
Rizling & Red & Abasár & 5.0 \\
\hline
\end{tabular}

The lower the $\mathrm{IC}_{50}$ value the higher the antioxidant activity.

\subsection{Extraction and fractionation}

The total extraction yield obtained in the first step of the process (Soxhlet extraction with EtOH $-\mathrm{H}_{2} \mathrm{O}$ ) was $19.4 \pm 1.2 \%$ (\% g extract/g dried plant material). Extraction curves obtained via fractionation of the alcoholic extract supported by cellulose with SFE are depicted in Figure 1. Extraction with pure $\mathrm{CO}_{2}$ at pressures less than $30 \mathrm{MPa}$ led to a negligible amount of extract (under 1.0\%). This value slightly increases with pressure up to $4.4 \%$ at $45 \mathrm{MPa}$. Addition of ethanol as a co-solvent led to a more relevant increase in the extraction yield due to the variation in the polarity of the supercritical fluid. SFE experiments with co-solvent revealed slightly increasing extraction yields with increasing ethanol concentrations at 30 $\mathrm{MPa}$, up to $8.0 \%$ with $15 \%$ ethanol.

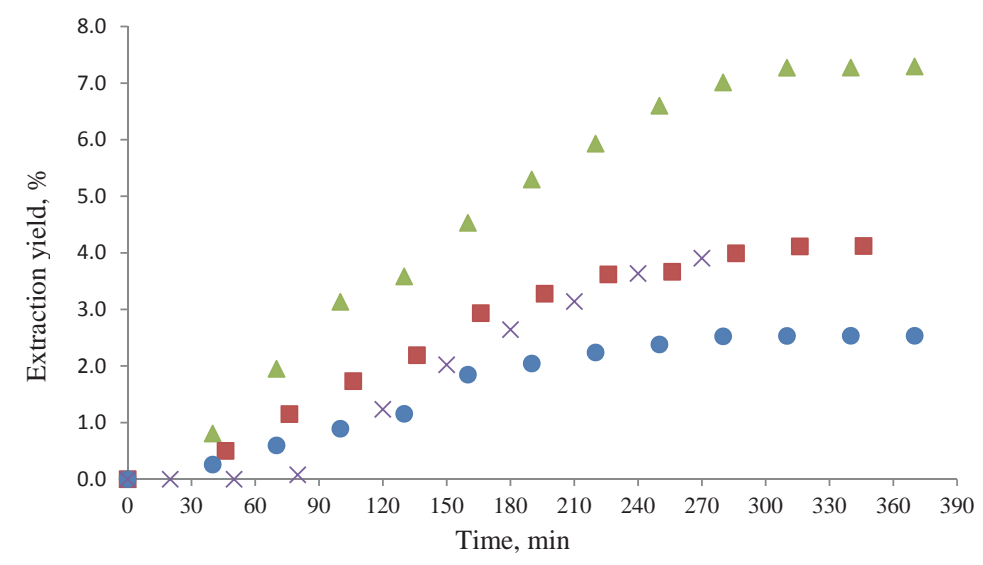

Fig. 1. Extraction curves of SFE on hydro-alcoholic extract $\left(\mathrm{P}=30 \mathrm{MPa}, \mathrm{T}=45^{\circ} \mathrm{C}\right)$

$\triangle$ : SFE_15\% ethanol, $\_$: SFE_10\% ethanol; $O$ : SFE_5\% ethanol; $X:$ SFE_0\% ethanol 
The bar diagrams in Figure 2 and Figure 3 show an evaluation of the antioxidant activity in terms of the $\mathrm{IC}_{50}$. Values of $\mathrm{IC}_{50}$ below $20 \mu \mathrm{g} \mathrm{ml}^{-1}$ were considered a relatively good antioxidant activity in comparison with the synthetic antioxidants like BHT. This compound was previously measured using the same method, showing a value for the inhibition coefficient 50 of $5.26 \pm 0.08 \mu \mathrm{g} \mathrm{ml}^{-1}$. SHARMA and BHAT (2009) reported $\mathrm{IC}_{50}$ values of 11.8 , 4.4 , and $60 \mu \mathrm{M}$ for ascorbic acid, propyl gallate, and BHT in methanol, respectively. To the contrary, high $\mathrm{IC}_{50}$ values $\left(>100 \mu \mathrm{g} \mathrm{ml}^{-1}\right.$ ) suggest pro-oxidant activity (CHOUEIRI et al., 2012).

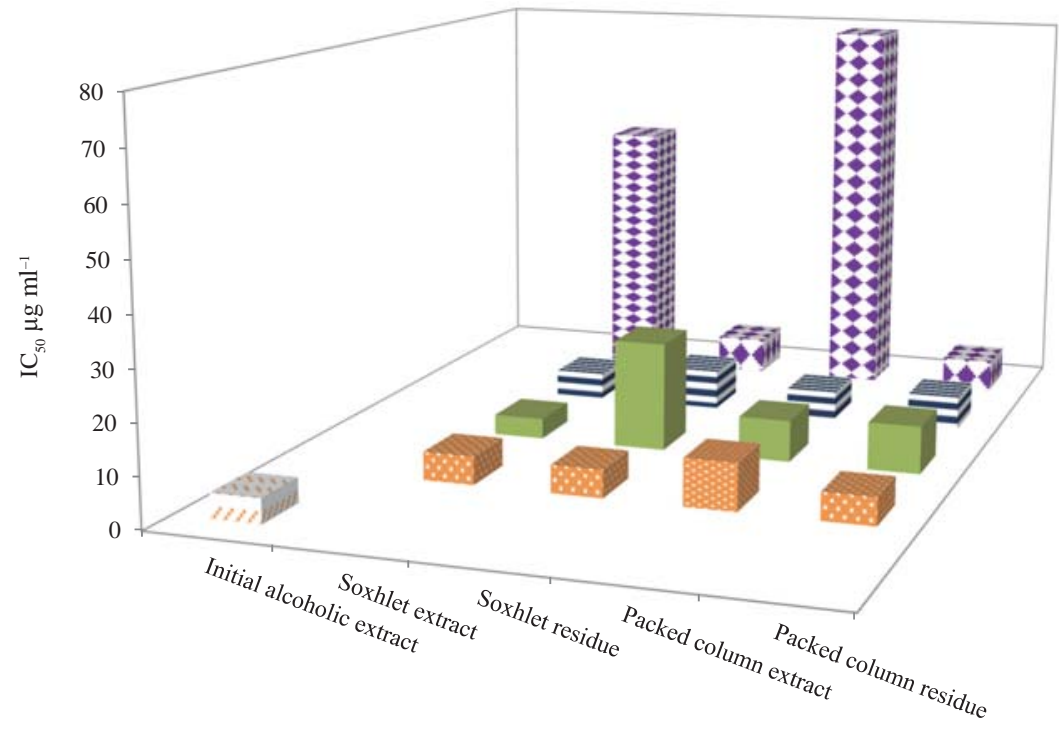

Fig. 2. Antioxidant activity of Soxhlet and packed column extracts and raffinates :Ethanol-water 50:50; : Ethanol; :: Acetone; =: Ethyl acetate; Hexane

In Figure 2 the possibilities of various organic solvents for further fractionation of the hydroalcoholic extracts are compared. The product obtained in the Soxhlet pilot plant extraction was fractionated by two conventional extraction techniques: packed column extraction and Soxhlet extraction (both at laboratory scale and atmospheric pressure).

Acetone appeared to be slightly selective to antioxidant compounds. On the contrary, hexane was slightly selective to non-antioxidant compounds or pro-oxidants, as the $\mathrm{IC}_{50}$ values of the extract in both packed column and Soxhlet extracts are high, compared to the initial hydroalcoholic extract. From the results in Figure 3, it can be observed that the supercritical carbon dioxide extracts obtained from fractionation of the hydroalcoholic extract present high pro-oxidant activity. The residues show relatively low values of $\mathrm{IC}_{50}$, showing their antioxidant potential. The $\mathrm{IC}_{50}$ of the extract with pure $\mathrm{CO}_{2}$ is much higher than that of the extract with hexane, while the extraction yields are similar. Adding ethanol as cosolvent to the carbon dioxide increases its polarity and in this case it leads to a decreasing selectivity of the solvent. Therefore, the best separation can be obtained by applying pure carbon dioxide as extractive agent. 


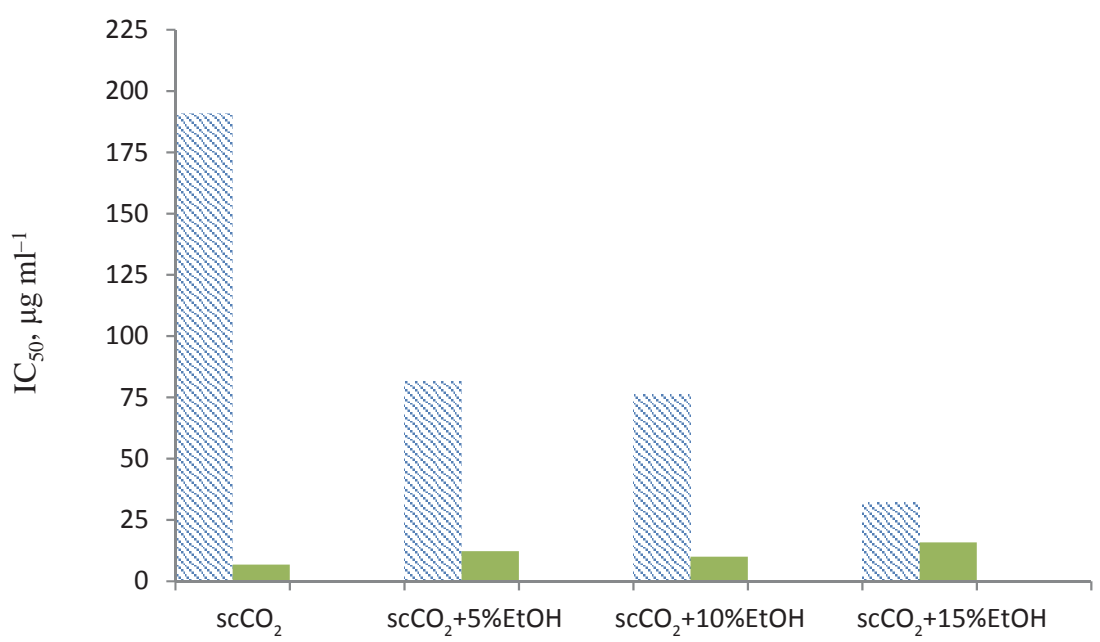

Fig. 3. $\mathrm{IC}_{50}$ values of SFE extracts and raffinates. $\square$ : raffinate, $\mathbb{N}$ : extract

\section{Conclusions}

The starting raw material, grape seed from Vitis vinifera, is a by-product from industry, which is often disposed of by the wineries. The developed extraction process is suitable to obtain two fractions with opposing antioxidant activity from the grape seed matrix. This material undergoes conventional alcoholic extraction with EtOH- $\mathrm{H}_{2} \mathrm{O}(50: 50 \mathrm{v} / \mathrm{v})$, followed by supercritical carbon dioxide extraction of the solidified hydroalcoholic extract. Studies of the pressure showed increasing yields by increasing pressure at constant temperature, in accordance with previous studies on pure Vitis vinifera (MOLERo GómEz et al., 1996; CAO \& ITO, 2003; Fiori et al., 2010; PAssos et al., 2010). Experiments with increasing concentration of ethanol in the supercritical fluid at constant temperature, pressure, and solvent-feed ratio also resulted in increasing extraction yields. Other authors reported not relevant differences in fatty acid composition of extracts from solvent extraction ( $n$-hexane) and SFE (CAO \& ITO, 2003), or those obtained by SFE of grape seeds with sequential fractionation (FIORI et al., 2010).

DPPH free radical scavenging assay revealed opposing antioxidant activity of the two fractions obtained in the presented two-step extraction process (Soxhlet extraction followed by SFE). These products might be exploitable in different ways in the pharmaceutical, food, or cosmetic industry as preservants, nutraceuticals or anticarcinogenics among others.

This research has received funding from the People Programme (Marie Curie Actions) of the European Union's Seventh Framework Programme FP7/2007-2013/ under REA grant agreement n 316959 (DoHip project, "Training Program for the Design of Resource and Energy Efficient Products by High Pressure Processes”). E. Székely was supported by the János Bolyai Research Fellowships of the Hungarian Academy of Sciences. 


\section{References}

CAO, X. \& ITo, Y. (2003): Supercritical fluid extraction of grape seed oil and subsequent separation of free fatty acids by high-speed counter-current chromatography. J. Chromatogr. A, 1021, 117-124.

CAtchpole, O.J., Grey, J.B., Durling, N.E. \& Dunn, K.G. (2007): Near-critical fluid extraction process. US Patent. WO 2007091901 A1, August 16, 2007.

Choueiri, L., Sanda, C.V., Calokerinos, A. \& Kefala, P. (2012): Antioxidant/pro-oxidant properties of model phenolic compounds. Part II: Studies on mixtures of polyphenols at different molar ratios by chemiluminescence and LC-MS. Food Chem., 133, 1039-1044

De Castro, L.M.D. (2010): Soxhlet extraction: Past and present panacea. J. Chromatogr. 1217, 2383-2389.

Dos Santos Freitas, L., Dariva, C., Assis, J.R. \& Bastos, C.E. (2013): Effect of experimental parameters in the pressurized liquid extraction of Brazilian grape seed oil. Sep. Purif. Technol., 116, 313-318.

EC (2009): Directive 2009/32/EC of the European Parliament and of the Council of 23 April 2009 on the approximation of the laws of the Member States on extraction solvents used in the production of foodstuffs and food ingredients. Annex I: Extraction solvents which may be used during the processing of raw materials, of foodstuffs, of food components or of food ingredients. OJ, 6.6.2009, L. 141/8-9.

European Pharmacopoeia Commission (2007): European Pharmacopoeia $6^{\text {th }}$ ed., Council of Europe, Strasbourg, chapter 2.2.32.

Fiori, L., Solana, M., Guella, G., Stim, C. \& Tosi, P. (2010): Grape seed oil: supercritical extraction, chemical analysis and fractionation, Conference paper, 12th European Meeting on Supercritical Fluids, May 2010, Graz (Austria).

Frankel, E.N., Waterhouse, A.L. \& Teissedre, P.L. (1995): Principal phenolic phytochemicals in selected Californian wines and their antioxidant activity in inhibiting oxidation of human low density proteins. J. Agr. Food Chem., 43, 890-894

Jayaprakasha, G.K., Selvi, T. \& Sakariah, K.K. (2003): Antibacterial and antioxidant activities of grape (Vitis vinifera) seed extracts. Food Res. Int., 36, 117-122.

Laws, D., Bath, N., Colin, S., Ennis, C., Pickett, J. \& Wheldon, A. (1980): Production of iso- $\alpha$-acid, US Patent 4212895, July 15.

Mishra, K., OJнA, H. \& Kumar, C.N. (2012): Estimation of antiradical properties of antioxidants using DPPH assay: A critical review and results. Food Chem., 130, 1036-1043.

Molero Gómez, A., Pereyra López, C. \& Martínez de la Ossa, E. (1996): Recovery of grape seed oil by liquid and supercritical carbon dioxide extraction: a comparison with conventional solvent extraction. Chem. Eng. J., 61, $227-231$.

Nakamura, Y., Tsuj, S. \& Tonogai, Y. (2003): Analysis of proanthocyanidins in grape seed extracts, health foods and grape seed oils. J. Health Sci., 40, 45-54.

Passos, C.P., Silva, R.M., Da Silva, F.A., Coimbra, M.A. \& Silva, C.M. (2010): Supercritical fluid extraction of grape seed (Vitis vinifera L.) oil. Effect of the operating conditions upon oil composition and antioxidant capacity. Chem. Eng. J., 160, 634-640.

Reverchon, E. \& Marco, I. (2006): Supercritical fluid extraction and fractionation of natural matter. J. Supercrit. Fluid., 38, 146-166.

Sharma, P. \& Bhat, T.K. (2009): DPPH antioxidant assay revisited. Food Chem., 113, 1202-1205.

Sovoví, H. (1994): Rate of the vegetable oil extraction with supercritical $\mathrm{CO}_{2}-$ I. Modelling of extraction curves. Chem. Eng. Sci., 49, 409-414.

ThiJssen, H.A. (1975): Solid-liquid packed bed extraction, US Patent, US 3862347 A, General Foods Corporation, January 21, 1975.

Valko, M., Leibfritz, D., Moncol, J., Cronin, M.T., Mazur, M. \& Telser, J. (2007): Free radicals and antioxidants in normal physiological functions and human disease. Int. J. Biochem. Cell B., 39, 44-84.

Wijngaard, H., Hossain, M.B., Dilip, K.R. \& Nigel, B. (2012): Techniques to extract bioactive compounds from food by-products of plant origin. Food Res. Int., 46, 505.

Zosel, K. (1981): Process for decaffeination of coffee, US Patent 4260639 A, April 7. 